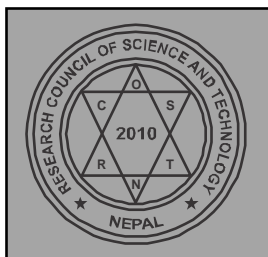

\title{
BIBECHANA
}

A Multidisciplinary Journal of Science, Technology and Mathematics

ISSN 2091-0762 (online)

Journal homepage: http://nepjol.info/index.php/BIBECHANA

\section{Fabrication of dye-sensitized solar cells from thin films of zinc oxide nanocrystalline particles and organic dye}

\author{
Bhim P. Kafle ${ }^{1 *}$, Babu R. Pokhrel ${ }^{2}$, Rajendra Gyawali ${ }^{1}$, Prakash Lamichhane ${ }^{1}$, Ravi M. Adhikari ${ }^{3}$ \\ ${ }^{1}$ Kathmandu University, Dhulikhel, Kavre, Nepal \\ ${ }^{2}$ Patan Multiple Campus, Tribhuvan University, Kathmandu, Nepal \\ ${ }^{3}$ Angstrom Technologies, Kentuki, USA \\ *Corresponding author: Email: bhimkafle@gmail.com \\ Accepted for publication: February 8, 2014
}

\begin{abstract}
Photovoltaic solar modules, which are mostly made of silicon based solar cells, are still expensive to the common people of Nepal. The high cost is, mainly, due to the processing difficulties to get pure crystalline silicon. Here, we present results on devising efficient and low-cost dye sensitized solar cells (DSSCs). The solar cells were fabricated from transparent thin film of zinc oxide ( $\mathrm{ZnO})$, as a semiconductor, on top of which a thin layer of synthetic organic dye was deposited for efficient light harvesting. In order to achieve the films with optimum conditions for solar cell fabrication, we prepared transparent thin films of $\mathrm{ZnO}$ of various thicknesses and characterized by measuring their light transmittance by UV-Visible spectrophotometry. The results clearly show variation in transmittance curves with variation in film's thickness.

Also for finding appropriate sensitizer for $\mathrm{ZnO}$ nanoparticles, we extensively investigated the light absorbance of synthetic organic dyes. Among the dye species investigated, Green-VS, Patent-Blue, and Black-ADLI show strong absorbance over the wide range in the visible spectrum, demonstrating prospect of utilizing for DSSCs. Then prototype solar cells from $\mathrm{ZnO}$ film with various thicknesses were constructed and were sensitized with the mixture of Green-VS and Black-ADLI dyes (with 1:1 ratio). The measured photo-voltage and photo-current from solar cell, from our modest $\mathrm{ZnO}$ film, after irradiation with $200 \mathrm{~W}$ commercial bulb (calibrated with Pyranometer) as a light source, were about $20 \mathrm{mV}$ and $1 \mu \mathrm{A}$, respectively. Also, with increment of the power of radiation both the measured photo-current and photo-voltage increase. Performance of the cell in real sun condition has also been made. With the solar radiation power of $930 \mathrm{~W}$, the observed photo-voltage and photo-current were ca. $230 \mathrm{mV}$ and $50 \mu \mathrm{A}$, respectively.
\end{abstract}

(c) 2014 RCOST: All rights reserved.

Keywords: Absorbance; Dye; Maharanga bicolor; Green VS; Patent Blue; Black ADLI; Solar cell.

\section{Introduction}

Solar energy is considered to be one of the most promising solutions to meet energy demand and environmental challenge as a carbon-neutral energy source in both developed and developing countries. Photovoltaic (PV) electric power generation is a technology for generating renewable energy from solar irradiation. Due to difficult geographical features (high hills and mountains) of Nepal, which create hurdles to extend national electrical grid to remote areas, PV technology is even more important than other countries. 
Recently published report of Nepal government reveals that electricity has reached to only $67 \%$ of the households for fulfilling their lighting needs. Still $18 \%$ rely on kerosene lamps while around $7 \%$ depend on solar energy technology for lighting [1]. Although the later data (use of solar energy) is quite encouraging, the use of the current PV technology is still very expensive to the common people of Nepal and is unaffordable unless government provides heavy subsidies for purchasing them. Therefore, for efficient harnessing of solar energy at low cost, modification in the present technology must be made.

In this connection, current PV devices (solar cells) in market, mostly, are made of crystalline silicon and amorphous silicon. However, because of the considerably high material costs and long energy payback time, effort has been made to find alternative materials such as compound semiconductor (for e.g. Gallium arsenide (GaAs) [2,3], copper indium gallium selenide [4,5] and thin film based solar cells [68]). But, for practical use, they still require major breakthroughs to meet the long term goal of very-low cost and short payback time so that the technology can be affordable to people of developing countries like Nepal for its adoption. Also long term stability is another problem of solar cells of the later type.

The thin film based dye sensitized solar cells (DSSCs) are made of oxide semiconductors and metallorganic complex dye (as a sensitizer), liquid electrolyte (medium for charge transfer from elctrode to dye), and two transparent conducting pieces of glass, contacting the particle film and the electrolyte. A thin layer (thickness in the range of hundreds of nanometer to micrometer) of metal oxide is coated on top of conducting glass and on top of $\mathrm{ZnO}$ layer another layer of dye is deposited. Then the counter electrode and dye layer are contacted with liquid electrolyte. This arrangement creates the large particle-dyeelectrolyte interface needed for cell operation. Operating principle of DSSC cell can be understood as: When photons (from sunlight) hit the photosensitive dye layer, the freed electrons accumulate on the layer of compound semiconductor (titanium dioxide or zinc oxide) and create an electrical current. Also a liquid electrolyte such as tri-odide anion $\left(\mathrm{I}_{3}{ }^{-}\right)$carries the electrons from counter electrode to dye layer. The schematic view of this type of solar cell is given in Fig. (1).

The overall process after irradiation with light of energy (hv), h being Planck constant, can be represented as:

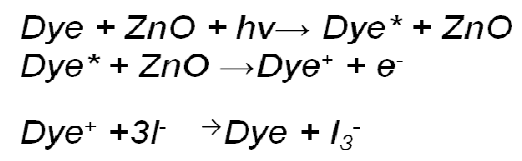

Here, $D y e^{*}$ represents excited dye molecule.

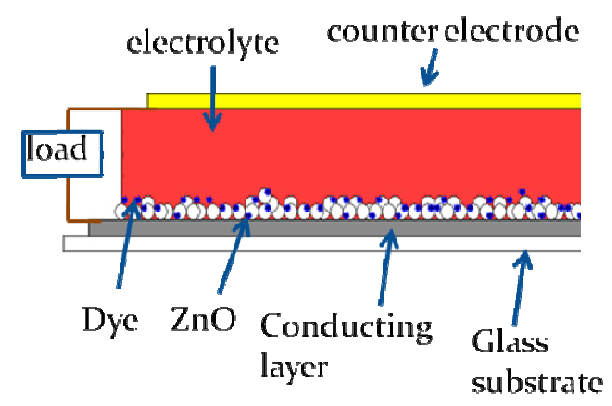

Figure (1): Schematic view of dye sensitized solar cell. White spheres indicate $\mathrm{ZnO}$ nanoparticles, while black spheres denote dye molecules.

The nanoparticle DSSC has already a comparable efficiency (meaning that 12 percent of the captured solar energy is converted to electrical energy) to traditional solid state solar cells and is inexpensive to manufacture. However, one of the measure problems of the DSSCs is still low solar to light conversion efficiency. Also, of their long term stability is another problem.

However, very recently, Yella et al. [8] reported that solar cells fabricated utilizing Cobalt (II/III)-based redox electrolyte in combination with the donor-bridge-acceptor zinc porphyrin dye (designated as YD2o-C8) as a sensitizer performed well. Specifically, solar cells with the later combination showed improvement in efficiency above $12 \%$ with photo-voltage of $\sim 1 \mathrm{~V}$. The reason of the better performance 
was explained as the use of YD2-o-C8 dye, which greatly retards recombination (the rate of interfacial back electron transfer from the conduction band of the nanocrystalline titanium dioxide $\left(\mathrm{TiO}_{2}\right)$ film to the oxidized cobalt mediator.

For the most part $\mathrm{TiO} 2$ has been the material of choice for dye-sensitized solar cells and so far have shown to exhibit the highest overall light conversion efficiency of $12 \%$ (above example). However, $\mathrm{ZnO}$ has also been recently explored as an alternative material, because of its low-cost, having similar bandgap to $\mathrm{TiO} 2$ and much higher electron mobility than $\mathrm{TiO} 2$. Nevertheless, the highest overall light conversion efficiency obtained so far for $\mathrm{ZnO}$ is only $~ 5-7 \%$ depending on the nature of $\mathrm{ZnO}$ composition and dye used for its ( $\mathrm{ZnO}$ film) sensitization [9].

Here, we report on progress in the direction of producing an efficient and low-cost dye sensitized solar cells (DSSCs) from $\mathrm{ZnO}$ thin film as a semiconductor. For cell construction, thin layer of organic dye was deposited on top of $\mathrm{ZnO}$ film. Iodine-based redox system was utilized as an electrolyte for efficient charge transfer between counter electrode (cathode) and dye. As quality of $\mathrm{ZnO}$ film (geometry and surface morphology) of the film greatly affect the photovoltaic properties of the cell, optimization of the films is discussed. Also, to tackle with efficiency reduction due to charge recombination [9], we have extensively searched natural organic dyes which demonstrate better light absorption coefficient and presented. Finally, the performance of our proto-type solar cells in the laboratory conditions is presented.

\section{Detailed Methodology}

For constructing solar cell with better performance, optimization of prepared $\mathrm{ZnO}$ thin films in terms of size (thickness and surface area) and surface morphology is required. Also, identification of a suitable sensitizer with a high molar extinction coefficient in visible region, for improving incident photon to current production, is another necessary condition for efficient solar cell. And, finally, assembling of all the components systematically for fabrication of proto-type dye sensitized solar cell and its characterization with proper care is another important task. Below we discuss methods to accomplish all of the above mentioned tasks in five steps.

\section{(a) Preparation and characterization of $\mathrm{ZnO}$ thin film on conducting glass substrate}

Preparation of transparent thin films of $\mathrm{ZnO}$ performed by depositing the $\mathrm{ZnO}$ precursor solution on conducting glass substrates $(2.5 \times 2.5 \times 0.25 \mathrm{~cm})$ by a spray pyrolysis method and details of which is given somewhere else $[10,11]$. Briefly, the setup consists of a cylindrical nebulizer mounted vertically on a horizontal table to spray the aerosol jet aimed upwards at a substrate through a $0.9 \mathrm{~mm}$ nozzle. The substrate is mounted on a temperature controlled heating block $25 \mathrm{~mm}$ above the nozzle. Humid air at atmospheric pressure is used as a carrier gas at a $2-3 \mathrm{~mL} / \mathrm{h}$ flow rate. The precursor solution consists of $0.2 \mathrm{M}$ acetate dissolved in distilled water and ethanol (at ratio of 1:3). Spraying times has been variable to control the thicknesses of the film. Alternatively, thicker films can be obtained in shorter times by increasing the concentration of the solution. After deposition, sample is annealed in a standard furnace $450^{\circ} \mathrm{C}$ for $1 \mathrm{~h}$ in oxygen. During the time of deposition the substrate temperature was maintained around $425 \pm 25$. The substrate temperature has been measured by IR thermometer (spectral response $6214 \mathrm{~mm}$ ) available in our laboratory. Transmission measurements have been performed on films supported by glass substrate using Genesis-10 UV Spectrophotometer (Thermo Scientific, UK, available in our department) in the wavelength range from 310 to1100 $\mathrm{nm}$.

\section{(b) Investigation of dye for photo-sensitizer}

Methods for characterization of dye samples have been discussed in our previous article [12]. In brief, the synthetic dye samples were purchased from Hindustan Ciba Geigy Ltd. Absorbance of the dye was measured on Genesis-10 UV-Visible Spectrophotometer in the wavelength of 310 to $900 \mathrm{~nm}$. 


\section{(c) Coating of $\mathrm{ZnO}$ film with dye}

Coating of $\mathrm{ZnO}$ thin film with dye is done by adsorption method for several minutes to 48 hours depending on the dye adsorption on the thin film. Here, to tackle the problem of efficiency reduction due to charge recombination we adopted following strategy: we have extensively searched natural organic dye which showed better light absorption coefficient, demonstrated reduced recombination, and higher stability, when compared with zinc porphyrin dye (standard dye). Utilizing the dye with above properties, we fabricated solar cells, a foremost component of the PV system. With this configuration, we expect to improve the cell's efficiency and other photovoltaic properties.

\section{(d) Fabrication of solar cell}

The solar cell was constructed by sandwitching two electrodes; anode (conducting glass electrode with thin layers of $\mathrm{ZnO}$ nanoparticles and dye molecules) and cathode (counter electrode). Then both of the electrodes were then squeezed together, using a spring type clamp. The electrolyte, KI / I2 was attracted into the cavities of the $\mathrm{ZnO}$ electrode by capillary forces.

\section{(e) Characterization of solar cells}

Measurement of the photocurrent versus photo-voltage (I-V) of the constructed solar cells was carried out in our laboratory condition at KU using Multimeter. The light intensity of the radiation was measured by a Pyranometer (PMA2144).

\section{Results and Discussion}

\section{(a) Thickness dependence transmittance of $\mathrm{ZnO}$ films}

Films of various thicknesses of $\mathrm{ZnO}$ were deposited on conducting glass (fluoride doped glass substrate) purchased from Merk, Germany. Fig. (2) shows precursor solution deposition time dependence of transmittance of $\mathrm{ZnO}$ thin films as a function of radiation wavelength. In other words, the figure resembles thickness dependence of transmittance of transparent films. The concentration of the precursor solution, zinc acetate, was $0.2 \mathrm{M}$. One can notice clearly that transmittance decreases gradually with the increment of deposition time, as expected, yielding only around $65 \%$ transmittance at the first peak position of spectrum from left for film obtained by our thickest film (20 minutes deposition time). The presence of noticeable oscillations in the transmittance versus wavelength spectra indicates that the films are of good quality.

\section{(b) Absorbance of Natural- and Synthetic- dyes: Prospect of application in DSSCs}

For our solar cell, we attempted to utilize organic synthetic dye. Characterization of their optical properties has been discussed in our previous article [12]. In brief, among all the samples, the GreenVS and PatentBLUE exhibited superior absorbance in the visible region (around $550 \mathrm{~nm}$ to $700 \mathrm{~nm}$ ). Interestingly, both dyes behaved similarly in this region and showed maximum absorbance at $650 \mathrm{~nm}$ with a FWHM around $60 \mathrm{~nm}$. On the other hand, BlackADLI showed fairly good absorbance in wide region extending from $\mathrm{UV}$ to visible region of electromagnetic

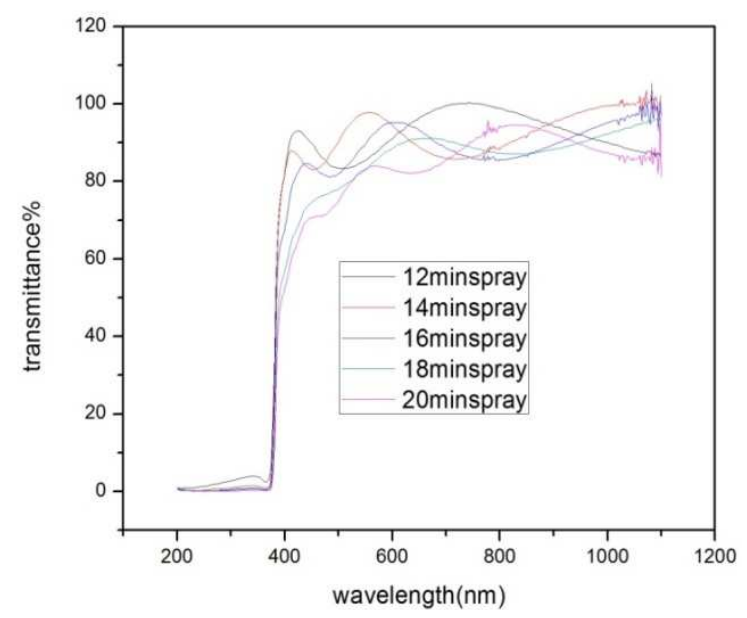

Figure 2: Precursor solution deposition time dependence of transmittance of light as a function of radiation wavelength.

(Note the decreasing trend of transmittance in the rising edge region of the curves with increasing in thickness of the films.) 
spectrum (300 nm to $700 \mathrm{~nm}$ ), with two major peaks at around 310 and $575 \mathrm{~nm}$. Indeed, the BlackADLI is demonstrates even better absorbance than Ruthenum dye complex, Z917, which have been common dye for DSSCs due to its remarkable absorbance in the visible region.

\section{(c) Fabrication and characterization of proto-type solar cell}
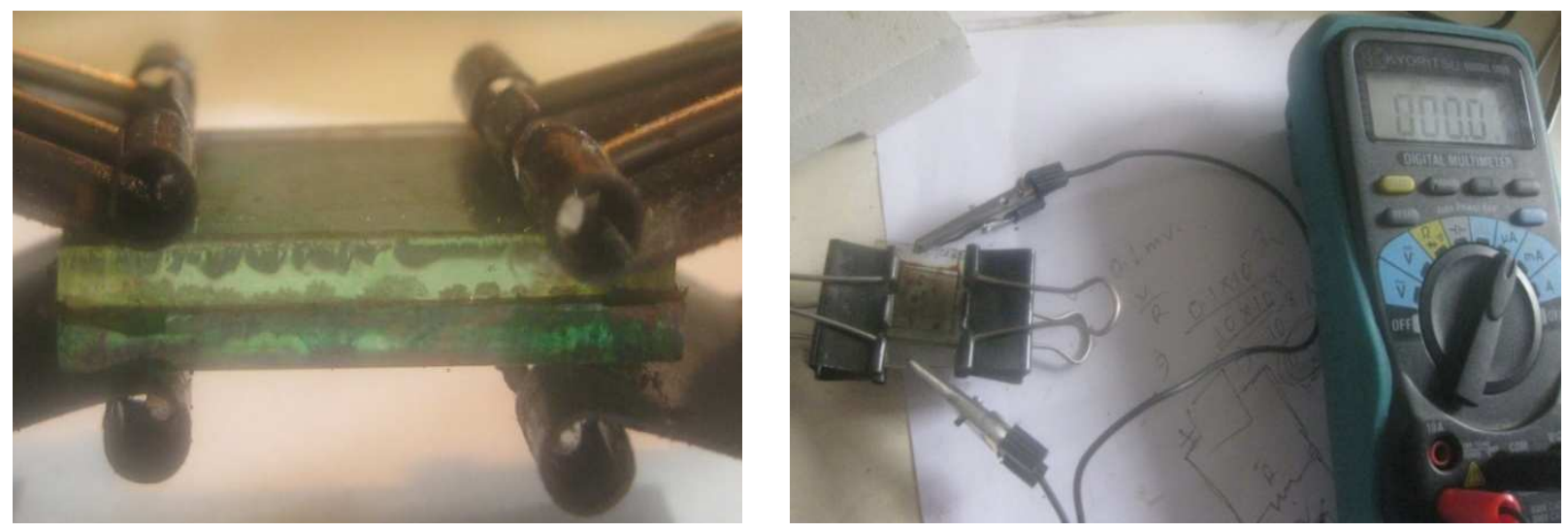

Figure 3: Side view (left) and top view of our proto-type dye sensitized solar cell hold by clamps at the ends. Both the electrodes of the cell shown at right are connected to multimeter for current and voltage measurements.

Prototype solar cells from $\mathrm{ZnO}$ film with various thicknesses were constructed. Left panel of Fig. 3 shows an image of one of the ptoto-type solar cells constructed in our laboratory. Both the anode (top) and cathode (buttom) electrodes of the cell are connected with Multimeter for current and voltage measurements. Anode was constructed by depositing $\mathrm{ZnO}$ nanoparticles on the FTO coated conducting glass substrate, utilizing optimized conditions for $\mathrm{ZnO}$ films on quartz substrate (see Fig.1). Then on top of $\mathrm{ZnO}$ layer a thin layer of organic dye was deposited (for this, $\mathrm{ZnO}$ films were soaked in dye solution for 46 hours). The mixture of Green-VS and Black-ADLI dyes (with 1:1 ratio) was used as a sensitizer. Then the performance of the cell was tested by measuring photo-voltage and photo-current, after irradiation with light source of various powers in the laboratory. As an example, the measured photovoltage and photo-current obtained from solar cell with intermediate thickness of $\mathrm{ZnO}$ film (40 minutes spray time of $\mathrm{ZnO}$ precursor solution) after irradiation with $200 \mathrm{~W}$ commercial bulb as a light source yielded photo-voltage of ca. $20 \mathrm{mV}$ and current of $0.7 \mu \mathrm{A}$, respectively. The values of current and voltage obtained from our systematic measurement with various powers from light source are displayed in table (1) and also Fig. (4). Note that with increment of the power both the measured photo-current and photo-voltage increase and show linear relationship.

Table (1): Measured photo-current and photo-voltage at various radiation powers. The commercial bulbs were used as a light souce, calibrated with the help of pyranometer (PMA2144).

\begin{tabular}{|c|c|c|}
\hline Power (Watt) & Voltage $(\mathbf{m V})$ & Current $(\boldsymbol{\mu A})$ \\
\hline 25 & 4.4 & 0.05 \\
\hline 40 & 6.6 & 0.1 \\
\hline 60 & 9.0 & 0.2 \\
\hline 100 & 13.5 & 0.3 \\
\hline 200 & 19.4 & 0.7 \\
\hline
\end{tabular}


Also, we tested our solar cell with above combination (same cell which was used to produce above data) in real sun condition as well (see Fig.(5)). With this cell, the best photo-voltage was ca. $230 \mathrm{mV}$ and ca. photocurrent was ca.50 $\mu \mathrm{A}$. Note that both the background current and voltage were zero. The power of radiation was $930 \mathrm{~W}$ as displayed by pyranometer.

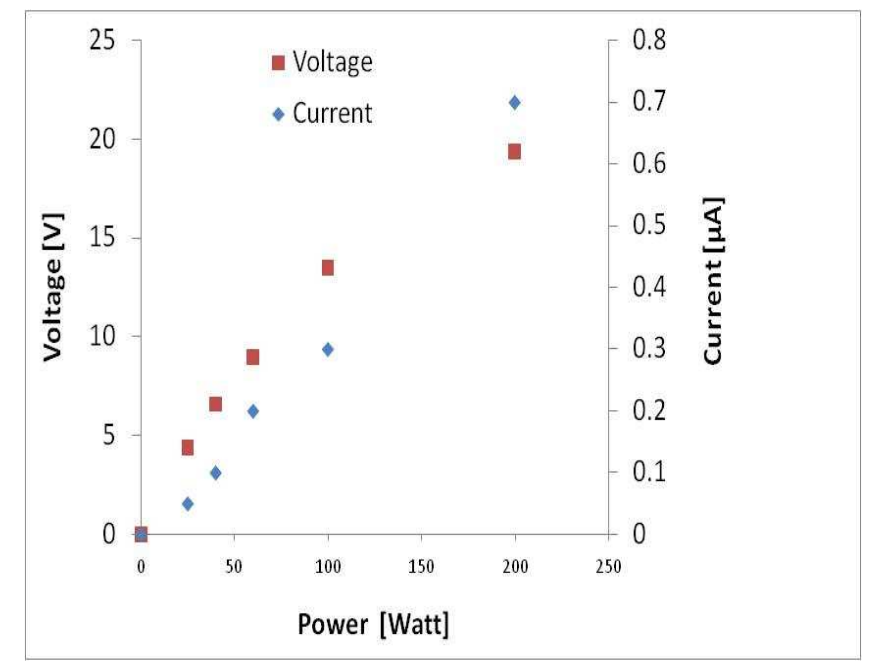

Figure 4: Measured photo-voltage and photocurrent as a function of radiation power. (Note the linear relationship between power and both the measured photo-current and photo-voltage.)
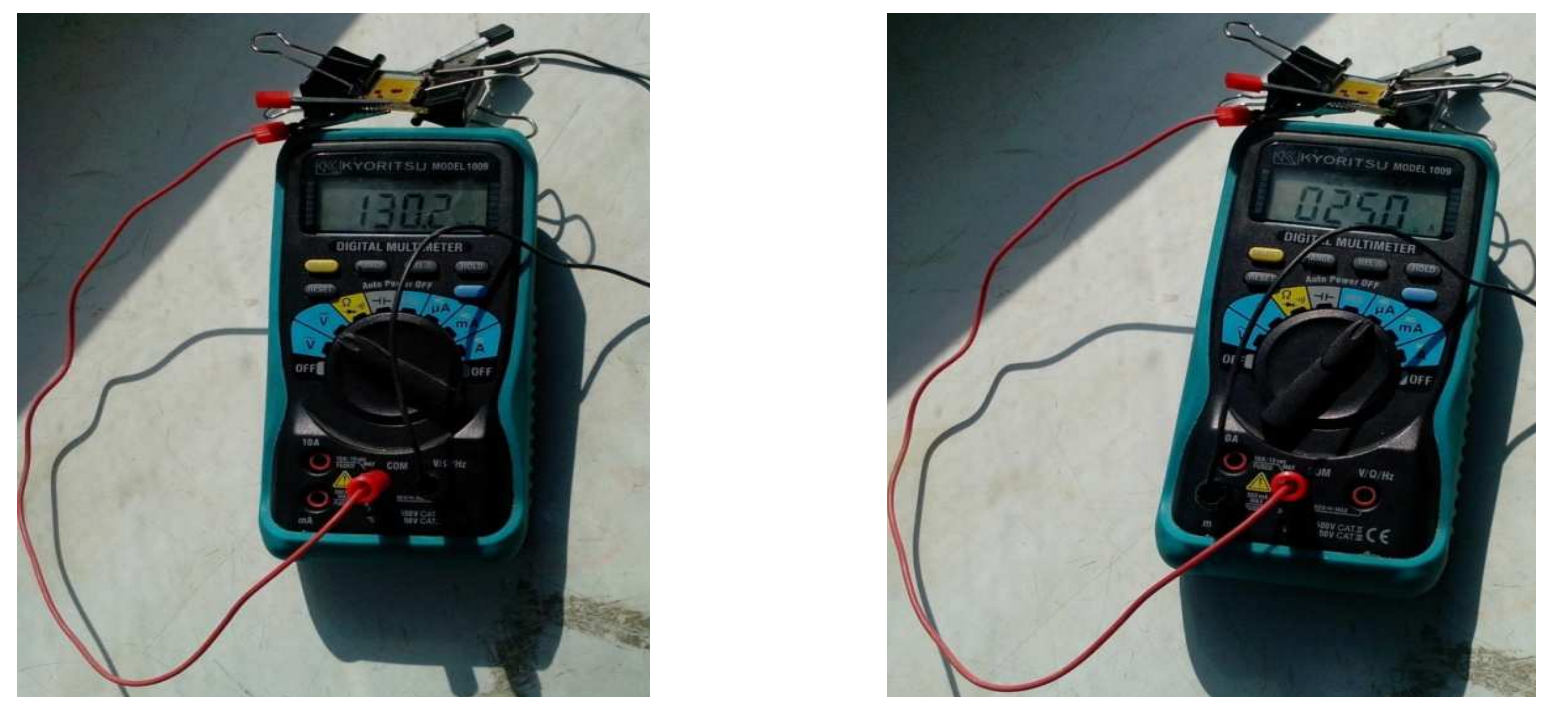

Figure 5: Test of our dye sensitized solar cell (top) in real sun condition.

The power of radiation was ca. $930 \mathrm{~W}$. The cell was hold by clamps at the ends and connected to Multimeter. The values on display of multimeter associate voltage (left) and current (right).

\section{Conclusion and Future outlook}

We managed to prepare transparent thin film of zinc oxide on conducting glass. Thickness dependence transmittance of the films have been measured and presented in this report. Properties such as accurate thickness, surface morphology, crystallinity, and conductivity are yet to be measured to fully characterize them. These measurements along with the transmittance will allow us to find the best condition to fabricate films with optimum properties for solar cells. Moreover, among the measured absorption spectra of synthetic dyes Green-VS, Patent-Blue, and Black-ADLI show strong absorbance over the wide range in the visible spectrum, demonstrating the prospect of utilizing in the fabrication of dye sensitized solar cells. 
B.P. Kafle et al. / BIBECHANA 11(1) (2014) 53-59: (Online Publication: March, 2014) p.59

The solar cells were also tested in real sun condition as well. With solar radiation power of $930 \mathrm{~W}$, the observed photo-voltage and photo-current were ca. $230 \mathrm{mV}$ and $25 \mu \mathrm{A}$. The observed values were remarkable in that they were obtained by a proto-type solar cell. Evaluation of efficiency and other photovoltaic parameters is in progress. Also, from the analysis so far what can be inferred is that, to make these solar cells competitive (or even cheaper) with commercial solar cells, further optimization is required. In particular, the present values of current and voltages have to be improved, at least, by factor of four. This is indeed possible by finely tuning the particle size of $\mathrm{ZnO}$ nanoparticles, film's thickness and making appropriate choice of sensitizer (dye). Also to fully characterize solar cell, photovoltaic parameters should be measured at standard photovoltaic conditions (AM 1.5 global sunlight at 1000 $\mathrm{W} / \mathrm{m}^{2}$ and a temperature of $298 \mathrm{~K}$ ) with a calibrated solar simulator.

\section{References}

[1] D. Adhikari, Energy Planning and Policy, The Himalayan Times (Daily News Paper) Jan. 15, 2013.

[2] J. S. Ward, K. Ramanathan, F. S. Hasoon, T. J. Coutts, J. Keane, M. A. Contreras, T. Moriarty, R. Noufi, Prog. Photovoltaics, 10 (2002) 41.

[3] M. Afzaal, P. O’Brien, J. Mater. Chem., 16 (2006) 1597.

[4] H. W. Schock, Appl. Surf. Sci., 92 (1996) 606.

[5] R. W. Birkmire, Energ. Mat. Sol. C, 65 (2001) 17.

[6] B. O’Regan, M. Grätzel, Nature, 353 (1991) 737.

[7] M. Gratzel, J. Photochem. Photobiol. C, 4 (2003) 145.

[8] A. Yella, H-W Lee, H. N. Tsao, C. Yi, A. K. Chandiran, Md. K. Nazeeruddin, E. W-G. Diau, C-Y Yeh, S. M. Zakeeruddin, M. Grätzel, Science, 334 (2011) 629.

[9] J. A. Anta, E. Guillen, R. Tena-Zaera, J. Phys. Chem. C, 116 (2012) 11413.

[10] A. Huczko, A. Dabrowska, D. K. Madhup, D. P. Subedi, S. P. Chimouriya, Phys. Status Solidi B, 247 (2010) 3035.

[11] B. P. Kafle, B. R. Pokhrel, P. Lamichhane, J. of Kathmandu University (2014) (In Press).

[12] B. P. Kafle, B. R. Pokhrel, R. Gyawali, A. Kafle, T. M. Shrestha, R. Bajracharya, R. M. Adhikari, Advances in Applied Science Research, 5 (2014) 8. 